\title{
Effect of plasma colloid osmotic pressure on intraocular pressure during haemodialysis
}

\author{
Takanobu Tokuyama, Tomohiro Ikeda, Keiko Sato
}

\begin{abstract}
Background-In a previous case report, it was shown that an increase in plasma colloid osmotic pressure induced by the removal of fluid during haemodialysis was instrumental in decreasing intraocular pressure. The relation between changes in intraocular pressure, plasma osmolarity, plasma colloid osmotic pressure, and body weight before and after haemodialysis is evaluated.

Methods-Intraocular pressure, plasma osmolarity, plasma colloid osmotic pressure, and body weight were evaluated before and after haemodialysis in 36 patients.

Results-Intraocular pressure and plasma osmolarity both decreased significantly after haemodialysis $(p<0.0001)$. Plasma colloid osmotic pressure increased significantly after haemodialysis $(p<0.0001)$. Body weight decreased significantly because of the removal of fluid during haemodialysis $(p<0.0001)$. No significant correlation was found between the change in intraocular pressure and that in plasma osmolarity $(r=-0.206, p=0.2297)$, whereas the change in intraocular pressure was correlated with the change in plasma colloid osmotic pressure $(r=-0.510$, $\mathrm{p}=0.0012)$ and the change in body weight $(r=0.534, p=0.0006)$. A significant correlation was found between the change in plasma colloid osmotic pressure and that in body weight $(r=-0.756, p<0.0001)$. Conclusion-The change in intraocular pressure was inversely correlated with the increase in plasma colloid osmotic pressure caused by the removal of fluid during haemodialysis.

(Br f Ophthalmol 1998;82:751-753)
\end{abstract}

Department of

Ophthalmology, Inoue

Hospital, Osaka, Japan

$\mathrm{T}$ Tokuyama

Department of

Ophthalmology, Osaka City General Hospital,

Osaka, Japan

T Ikeda

K Sato

Correspondence to: Takanobu Tokuyama, MD,

Department of

Ophthalmology, Inoue

Hospital, 16-17, Enoki-cho,

Suita City, Osaka 564, Japan.

Accepted for publication

22 January 1998

Telation between plasma osmolarity intraocular pressure (IOP) during haemodialysis has been studied since Sitprija and coworkers ${ }^{1-3}$ first reported that a rapid decrease in plasma osmolarity markedly increased the IOP during haemodialysis. The mechanism before and after haemodialysis

${ }^{\star}$ Change in value after haemodialysis.

†Student's paired $t$ test. they proposed for this increase was the movement of water from the plasma into the aqueous humour due to an osmotic disequilibrium between the two compartments caused by a rapid decrease in plasma osmolarity. ${ }^{3}$ Although a shift in water between these compartments is influenced by the plasma colloid osmotic pressure, the relation between IOP and plasma colloid osmotic pressure during haemodialysis has not been investigated.

We recently reported a patient with neovascular glaucoma who exhibited a marked decrease in IOP accompanied by an increase in plasma colloid osmotic pressure, even though plasma osmolarity remained virtually constant during haemodialysis. ${ }^{4}$ The present study evaluated the relation between changes in IOP, plasma osmolarity, plasma colloid osmotic pressure, and body weight before and after haemodialysis.

\section{Patients and methods}

A total of 36 patients who were receiving haemodialysis (mean age 57.6 years, range 30-81 years) without ocular disease were enrolled in this study. After informed consent for participation had been obtained, IOP, plasma osmolarity, plasma colloid osmotic pressure, and body weight were measured before and after haemodialysis. All patients were dialysed for a mean of 3.8 hours (ranged 3-4.5 hours) at the Inoue Hospital. IOP was determined by Goldmann applanation tonometry. Plasma osmolarity was measured by freezing point depression. Plasma colloid osmotic pressure ${ }^{5}$ was calculated from the formula: plasma colloid osmotic pressure $=5.5 \times$ concentration of plasma albumin $+1.4 \times$ the concentration of plasma globulin. The change in body weight represents the amount of fluid removed during haemodialysis.

Data are presented as mean (SD). Statistical evaluation tests utilised the Student's paired $t$ test and Pearson's coefficient test. A level of $p$ $<0.05$ was accepted as statistically significant.

Results

The IOP, plasma osmolarity, plasma colloid osmotic pressure, and body weight in the 36

Table 1 Intraocular pressure (IOP), plasma osmolarity, plasma colloid osmotic pressure, and body weight in 36 patients

\begin{tabular}{lllll}
\hline & $\begin{array}{l}\text { Before haemodialysis } \\
(\text { mean }(S D))\end{array}$ & $\begin{array}{l}\text { After haemodialysis } \\
(\text { mean }(S D))\end{array}$ & $\begin{array}{l}\Delta^{*} \\
(\text { mean }(S D))\end{array}$ & $p$ Valuet \\
\hline IOP of right eye $(\mathrm{mm} \mathrm{Hg})$ & $13.6(2.7)$ & $11.9(2.0)$ & $-1.8(2.0)$ & $<0.0001$ \\
IOP of left eye $(\mathrm{mm} \mathrm{Hg})$ & $13.6(2.6)$ & $11.8(2.0)$ & $-1.8(2.1)$ & $<0.0001$ \\
Plasma osmolarity $(\mathrm{mOsm} / \mathrm{l})$ & $311.9(8.4)$ & $296.2(8.6)$ & $-15.7(9.0)$ & $<0.0001$ \\
Plasma colloid osmotic pressure $(\mathrm{mm} \mathrm{Hg})$ & $26.2(1.4)$ & $29.9(3.4)$ & $3.8(3.0)$ & $<0.0001$ \\
Body weight $(\mathrm{kg})$ & $49.8(6.2)$ & $47.5(6.0)$ & $-2.2(0.9)$ & $<0.0001$ \\
\hline
\end{tabular}



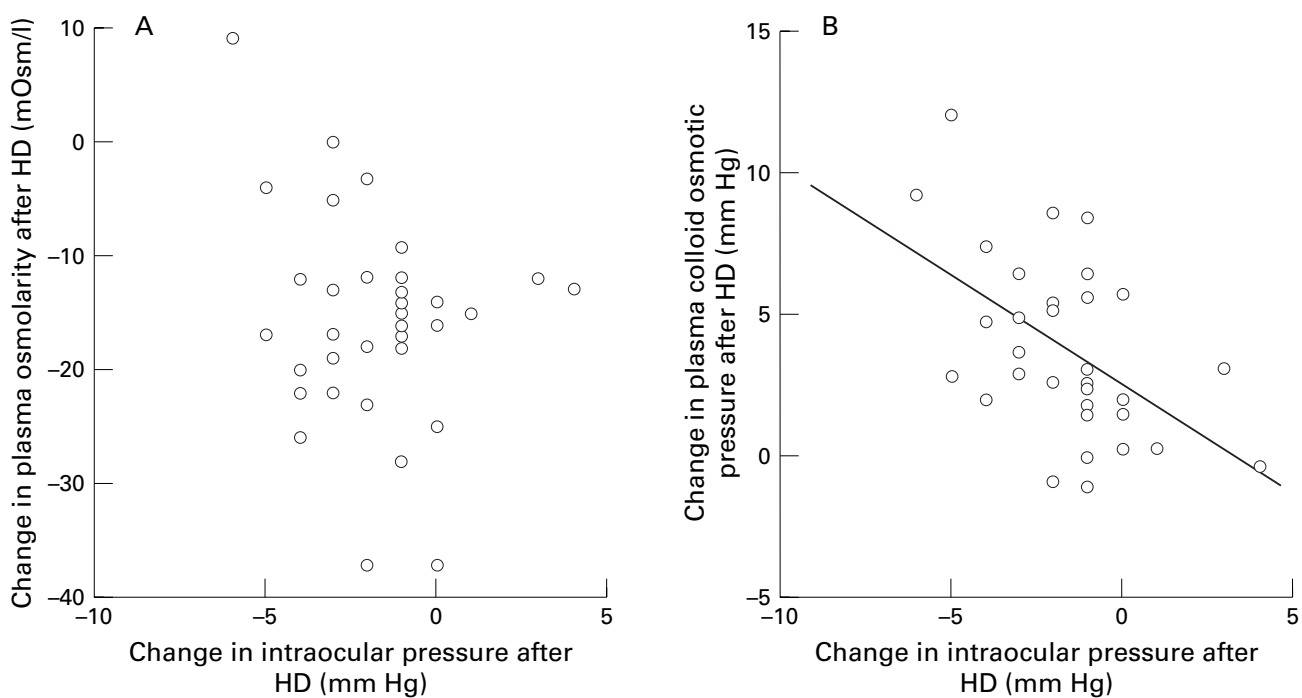

Figure 1 (A) The lack of significant correlation between the change in intraocular pressure (IOP) and that of plasma osmolarity after haemodialysis (HD) $(r=-0.206 p=0.2297)$. (B) Correlation between the change in IOP and that of plasma colloid osmotic pressure after HD $(r=-0.510, p=0.0012)$.

patients before and after haemodialysis are shown in Table 1 . The IOP decreased significantly after haemodialysis (IOP of right eye went from 13.6 (SD 2.7) to $11.9(2.0) \mathrm{mm} \mathrm{Hg}$, $\mathrm{p}<0.0001$ : IOP of left eye went from $13.6(2.6)$ to $11.8(2.0) \mathrm{mm} \mathrm{Hg}, \mathrm{p}<0.0001)$. The change in IOP after haemodialysis was $-1.8(2.0) \mathrm{mm}$ $\mathrm{Hg}$ in the right eye and $-1.8(2.1) \mathrm{mm} \mathrm{Hg}$ in the left eye. Because there was no significant difference between IOP in both eyes, the IOP of the right eye was used in the analysis of data. Plasma osmolarity decreased significantly from 311.9 (8.4) to 296.2 (8.6) $\mathrm{mOsm} / 1$ after haemodialysis $(\mathrm{p}<0.0001)$, a change of -15.7 (9.0) $\mathrm{mOsm} / \mathrm{l}$. The plasma colloid osmotic pressure increased significantly from 26.2 (1.4) to 29.9 (3.4) $\mathrm{mm} \mathrm{Hg}$ after haemodialysis $(\mathrm{p}<0.0001)$, a change of 3.8 (3.0) $\mathrm{mm} \mathrm{Hg}$. Body weight decreased significantly from 49.8

Interstitial fluid $\quad$ Plasma $\quad$ Dialysate
(or aqueous humour)

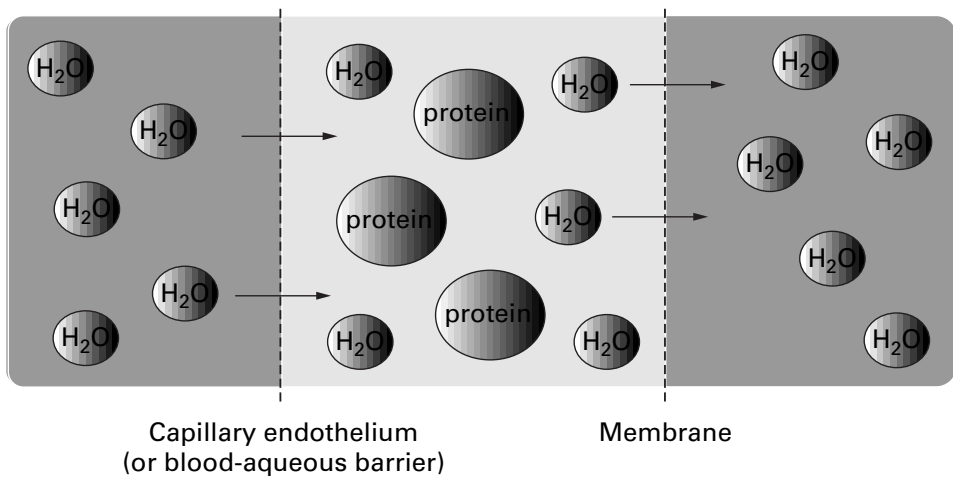

Figure 2 Schematic diagram illustrating the movement of water during haemodialysis. ${ }^{4}$ The mechanism for the correction of a massive accumulation of fluid in the interstitial compartment, and for the reduction in intraocular pressure is illustrated. As a first step, a net movement of water from plasma into dialysate is caused by haemodialysis. As a

consequence, plasma colloid osmotic pressure undergoes a relative increase in response to the decrease in plasma volume, because large proteins, such as albumin and globulin, cannot cross the membranes. A gradient of colloid osmotic pressure between plasma and interstitial fluid (or aqueous humour) causes a net movement of water from the interstitial fluid (or aqueous humour) into the plasma. Finally, the massive accumulation of interstitial fluid is corrected (or intraocular pressure decreases).
(6.2) to $47.5(6.0) \mathrm{kg}$ after haemodialysis $(\mathrm{p}<0.0001)$, a change of $-2.2(0.9) \mathrm{kg}$.

Figure 1 shows a lack of correlation between the change in IOP and that of plasma osmolarity $(r=-0.206, \mathrm{p}=0.2297)$, and a correlation between the change in IOP and that of plasma colloid osmotic pressure after haemodialysis $(r=-0.510, \mathrm{p}=0.0012)$. The change in IOP was also correlated with the change in body weight $(r=0.534, \mathrm{p}=0.0006)$, which was significantly correlated with the change in plasma colloid osmotic pressure after haemodialysis $(r=-0.756, \mathrm{p}<0.0001)$. There was no significant correlation between the change in plasma osmolarity and that of body weight $(r=-0.207$, $\mathrm{p}=0.2276$ ), and between the change in plasma osmolarity and that of plasma colloid osmotic pressure after haemodialysis $\quad(r=0.128$, $\mathrm{p}=0.4609)$.

\section{Discussion}

The chief objective of administering haemodialysis is to correct the composition and the volume of body fluids. The correction of body fluid composition seeks to eliminate uraemic substances and is concerned with the change in plasma osmolarity during haemodialysis. The correction of body fluid volume seeks to resolve the excessive accumulation and abnormal distribution of body fluid and is concerned with the change in plasma colloid osmotic pressure during haemodialysis. Although many studies $^{1-3} 6-15$ have examined the change in IOP during haemodialysis, most of them have concentrated on the relation between IOP and plasma osmolarity, because the plasma osmolarity usually changes during haemodialysis.

Fauchald $^{16}$ found plasma colloid osmotic pressure to be instrumental in the hydrodynamic changes that occur during haemodialysis; in brief, plasma volume decreases along with the removal of water by haemodialysis, and the concentration of plasma proteins such as albumin and globulin, increases, leading to 
an increase in plasma colloid osmotic pressure. The relative increase in colloid osmotic pressure caused by the removal of water by haemodialysis generates a gradient of colloid osmotic pressure between the plasma and interstitial fluid, causing water to shift from the interstitial fluid into the plasma; the rate of decrease in plasma volume then slows gradually. The rate of increase in plasma colloid pressure also slows, until the rate of the removal of water from plasma by haemodialysis equals the rate of shift in water from the interstitial fluid into the plasma. The increase in plasma colloid osmotic pressure tends to level off toward the end of haemodialysis. The excess amount of interstitial fluid is finally corrected without decreasing in the plasma volume (Fig 2).

Although the plasma colloid osmotic pressure, as well as plasma osmolarity, is involved in the hydrodynamic change, no previous studies have evaluated the relation between the IOP and the plasma colloid osmotic pressure during haemodialysis. We recently reported an elderly man with neovascular glaucoma whose IOP decreased markedly during haemodialysis. ${ }^{4}$ To evaluate the mechanism of this decrease, we measured plasma osmolarity, plasma colloid osmotic pressure, and body weight every 30 minutes during haemodialysis given for a period of 4.5 hours. IOP in the left eye with neovascular glaucoma decreased from $53 \mathrm{~mm}$ $\mathrm{Hg}$ at the beginning of haemodialysis to $14 \mathrm{~mm}$ $\mathrm{Hg}$ at its end. Plasma osmolarity remained almost constant during haemodialysis (295 $\mathrm{mOsm} / 1$ at the beginning; $305 \mathrm{mOsm} / 1$ at the end), but plasma colloid osmotic pressure increased $(23.0 \mathrm{~mm} \mathrm{Hg}$ at the start of haemodialysis; peak: $27.2 \mathrm{~mm} \mathrm{Hg}$ ). The patient's weight decreased by $5.7 \mathrm{~kg}$. These findings led us to suggest that the decrease in IOP was related to the increase in plasma colloid osmotic pressure caused by the removal of fluid during haemodialysis. In brief, plasma is separated from the aqueous humour by the blood-aqueous barrier and from the dialysate by the dialyser membrane. As the plasma volume decreases owing to the removal of water from the plasma into the dialysate during haemodialysis, there is a relative increase in the concentration of plasma proteins - that is, the plasma colloid osmotic pressure increases. As a result, water is pushed from the aqueous humour into the plasma causing a reduction in IOP (Fig 2).

Although there is conflicting evidence about the rate of osmolarity decrease that can induce an increase in IOP during haemodialysis, Sitprija and coworkers ${ }^{2}$ showed that a significant rise in IOP occurred in dogs when the change in plasma osmolarity was $11 \mathrm{mOsm} / 1 / \mathrm{h}$, but not when it was only $-8 \mathrm{mOsm} / \mathrm{l} / \mathrm{h}$. Gafter and coworkers ${ }^{11}$ reported that IOP did not increase significantly when the change in plasma osmolarity during haemodialysis was $-6 \mathrm{mOsm} / \mathrm{l} / \mathrm{h}$. Austin and coworkers ${ }^{14}$ showed that IOP did not change significantly when the change in plasma osmolarity during haemodialysis was $-7.7 \mathrm{mOsm} / \mathrm{l} / \mathrm{h}$. In our study, the change in plasma osmolarity during haemodialysis was $-4.1 \mathrm{mOsm} / \mathrm{l} / \mathrm{h}$. Thus, with modern techniques of haemodialysis a rise in IOP during the procedure is unlikely, but we believe that a change in IOP may be affected by plasma osmolarity as well as by plasma colloid osmotic pressure during haemodialysis. A decrease in plasma osmolarity may tend to increase IOP while an increase in plasma colloid osmotic pressure may tend to decrease IOP.

Our data indicate that a change in IOP was significantly correlated with the change in plasma colloid osmotic pressure caused by the removal of body fluid during haemodialysis. We have found that IOP tends to decrease during efficient haemodialysis as a results of the increase in plasma colloid osmotic pressure caused by the removal of fluid during haemodialysis. Plasma colloid osmotic pressure was instrumental in causing the decrease in IOP observed during haemodialysis.

1 Sitprija V, Holmes JH. Preliminary observations on the change in intracranial pressure and intraocular pressure during hemodialysis. Trans Am Soc Artif Intern Organs during hemo

2 Sitprija V, Holmes JH, Ellis PP. Changes in intraocular pressure during hemodialysis. Invest Ophthalmol 1964;3:27384.

3 Sitprija V, Holmes JH, Ellis PP. Intraocular pressure changes during artificial kidney therapy. Arch Ophthalmol 1964;72: 626-31.

4 Tokuyama T, Ikeda T, Sato K, et al. Marked decrease in intraocular pressure in a neovascular glaucoma patient during hemodialysis. fpn $\mathcal{f}$ Ophthalmol 1997;41:101-3.

5 Milnor WR. Capillaries and lymphatic vessels. In: Mountcastle VB, ed. Medical physiology. 12th ed. St Louis: CV castle VB, ed. Medical

6 Ramsell JT, Ellis PP, Paterson CA. Intraocular pressure changes during hemodialysis. Am $\mathcal{F}$ Ophthalmol 1971;72: 926-30.

7 Burn RA. Intraocular pressure during haemodialysis. $\mathrm{Br}$ f Ophthalmol 1973;57:511-3.

8 Wizemann A, Bernhardt O, Wizemann V. Untersuchungen zum Einfluß der Serumosmolarität, des Wasserentzuges und des Blutdruckes auf den intraocularen Druck am Modell der Hämodialyse, Hämofiltration und simultanen Hämofiltration/Hämodialyse. Albrecht von Graefes Arch Klin Exp Ophthalmol 1980;213:43-7.

9 Jaeger PH, Morisod L, Wauters JP, et al. Prevention of glaucoma during hemodialysis by mannitol and acetazolamide. N Engl f Med 1980;303:702.

10 Rever B, Fox L, Christensen R, et al. Adverse ocular effects of acetate hemodialysis. Am f Nephrol 1983;3:199-204.

11 Gafter U, Pinkas M, Hirsch J, et al. Intraocular pressure in uremic patients on chronic hemodialysis. Nephron 1985;40: $74-5$.

12 Sud RN, Ghhabra SC, Sandhu JS, et al. Intraocular pressure during haemodialysis. Indian f Ophthalmol 1988;36:74-5.

13 Broekema N, von Bijsterveld OP, de Bos Kuil RJC. Intraocular pressure during hemodialysis. Ophthalmologica 1988;197:60-4.

14 Austin JN, Klein M, Mishell J, et al. Intraocular pressures during high-flux hemodialysis. Renal Fail 1990;12:109-12.

15 Leiba H, Oliver M, Shimshoni M, et al. Intraocular pressure fluctuations during regular hemodialysis and ultrafiltration. Acta Ophthalmol 1990;68:320-2.

16 Fauchald P. Transcapillary colloid osmotic gradient and body fluid volumes in renal failure. Kidney Int 1986;29: 895-900. 